\title{
ANALISIS PROTOKOL CryptO-ON2 DENGAN MENGGUNAKAN SCYTHER TOOL
}

\author{
Esti Rahmawati Agustina ${ }^{1}$, Magdalena Christine ${ }^{2}$ Irma Fitriani $^{3}$ \\ 1,2,3Badan Siber dan Sandi Negara \\ Email: ${ }^{1}$ esti.rahmawati@bssn.go.id, ${ }^{2}$ magdalena.christine@bssn.go.id, ${ }^{3}$ irma.fitriani@bssn.go.id
}

(Naskah masuk: 28 November 2018, diterima untuk diterbitkan: 07 Januari 2019)

\begin{abstract}
Abstrak
Pemilihan Umum (pemilu) di Indonesia merupakan peristiwa yang sangat penting mengingat Indonesia merupakan negara yang menganut paham demokrasi. Metode yang digunakan dalam pemilihan umum di Indonesia adalah dengan menggunakan kertas suara yang ditandai yaitu dicentang atau dicoblos. Banyak kelemahan dan kecurangan yang terjadi dalam sistem konvensional ini. Misalnya pemilih ganda, data pemilih tidak valid, surat suara rusak dan lain sebagainya. Salah satu solusi untuk menyelesaikan permasalahan pada sistem pemilu konvensional adalah dengan menerapkan electronic voting (e-voting). Berbagai penelitian dan pengembangan dilakukan dalam rangka membangun sistem $e$-voting yang aman. Salah satunya adalah dengan mengimplementasikan teknik kriptografi. Salah satu protokol e-voting yang menerapkan teknik kriptografi adalah protokol CryptO-ON2. Pada perkembangannya, protokol ini telah dianalisis dengan menggunakan verifikasi formal berbasis pendekatan logika yaitu BAN Logic. Verifikasi formal terhadap suatu protokol dapat dijamin obyektivitasnya dengan menggunakan tools tertentu. Pada paper ini disajikan analisis protokol CryptOON2 dengan menggunakan Scyther Tool. Tool ini memeriksa klaim secrecy dan authentication dari protokol CryptO-0N2. Hasil menunjukkan dari 17 klaim (secrecy dan authentication) terdapat 10 klaim sukses dan 7 klaim gagal.
\end{abstract}

Kata kunci: kriptografi, protokol CryptO-ON2, Scyther Tool

\section{CryptO-0N2 PROTOCOL ANALYSIS USING SCYTHER TOOL}

\begin{abstract}
Elections in Indonesia is a very important event considering Indonesia is a democratic country. The method of the general election in Indonesia is use a marked ballot that is ticked or punched. Many weaknesses and frauds occur in this conventional system. For example multiple voters, invalid voter data, broken ballots and so forth. One solution to solve the problems in conventional electoral systems is to apply electronic voting (e-voting). Various research and development carried out in order to build a secure e-voting system. One of them is by implementing cryptographic techniques. One of the e-voting protocols employing cryptographic techniques is the CryptO-ON2 protocol. In its development, this protocol has been analyzed by using formal logic-approach based on logical verification that is BAN Logic. Formal verification of a protocol can be guaranteed objectivity by using certain tools. In this paper we present CryptO-ON2 protocol analysis using Scyther Tool. This tool examines the secrecy and authentication claims of the CryptO-ON2 protocol. The result shows from 17 claims (secrecy and authentication) there are 10 successful claims and 7 claims are failed.
\end{abstract}

Keywords: cryptography, CryptO-ON2 protocol, Scyther Tool

\section{PENDAHULUAN}

Pemilihan Umum (Pemilu) di Indonesia merupakan peristiwa yang sangat penting. Pemilu telah menjadi pesta rakyat. Hal ini dikarenakan Indonesia merupakan salah satu negara di dunia yang menganut paham demokrasi. Indonesia telah menyelenggarakan sebelas kali pemilihan umum yang berskala nasional yaitu pada tahun 1955, 1971, 1982, 1987, 1992, 1997, 1999, 2004, 2009, dan 2014 (www.kompas.com). Metode yang digunakan dalam pemilihan umum tersebut adalah dengan menggunakan kertas suara yang ditandai yaitu dicentang ataupun dicoblos. Berdasarkan artikel dari www.liputan6.com, metode pemilihan umum secara konvensional banyak memiliki kelemahan dan menimbulkan kecurangan. Misalnya pemilih ganda, data pemilih yang tidak valid, surat suara rusak dan lain sebagainya.

Seiring dengan pemanfaatan Teknologi Informasi dan Komunikasi (TIK) dalam kehidupan sehari-hari, banyak penelitian dilakukan untuk 
mencari alternatif solusi dalam menjawab tantangan terkait potensi kecurangan pada sistem pemilihan umum konvensional. Salah satu alternatif solusi tersebut adalah dengan electronic voting (e-voting). Jika diterapkan dengan tepat, sistem e-voting dapat mengurangi penipuan data, mempercepat pengolahan hasil pemilihan, dan meningkatkan aksesibilitas dalam pemilihan umum (Wolf, 2011). Pertengahan tahun 2009 di Kabupaten Jembrana (Bali), sistem ini pertama kali diterapkan. Sejak saat itu telah berpuluh kali pemilihan kepala dusun dilakukan dengan e-voting. Tercatat Kabupaten Jembrana telah menghemat anggaran sebesar $60 \%$.

Pada tanggal 30 Maret 2010, Mahkamah Konstitusi telah mengesahkan bahwa penerapan $e$ voting tidak melanggar konstitusi selama tidak melanggar asas Pemilu yaitu luber dan jurdil. Dengan demikian $e$-voting mungkin diterapkan pada skala yang lebih luas, misalnya Pemilihan Umum Kepala Daerah dan Wakil Kepala Daerah. Dengan pengesahan tersebut berbagai daerah telah menyambut positif dan menerapkan e-voting ini, misalnya Pemilihan Kades di Musi Rawas pada tahun 2014 (www.antaranews.com), Pemilihan Kepala Desa Benteng di Kapubaten Banyuasin pada tahun 2015 (www.tribunnews.com), Pemilihan Ketua RW 2 di Kelurahan Pulisen, Kecamatan Boyolali pada tahun 2017 (www.jatengpos.com), dan lain sebagainya.

Teknik kriptografi dapat diimplementasikan untuk membangun sistem e-voting yang aman (Scheiner, 1996). Menurut Menezes, kriptografi adalah ilmu yang mempelajari teknik-teknik matematika yang berhubungan dengan aspek-aspek keamanan informasi seperti kerahasiaan data, keabsahan data, integitas data, serta authentication data (Menezes, 1997). Pada tahun 2012, Prakasa memperkenalkan salah satu protokol $e$-voting yang menggunakan fitur-fitur kriptografi dengan nama protokol CryptO-0N2 (Prakasa, 2012). Protokol ini merupakan protokol secure ubiquitus e-voting yang menggunakan fitur-fitur kriptografi yaitu fungsi hash dan asimetrik (penggunaan kunci privat dan kunci publik) untuk menjamin keamanan transmisi data. Protokol ini mempunyai sifat ubiquitus. Sifat ini mendukung proses pemilihan dapat dilakukan dimana saja, kapan saja, dan bagaimana saja. Untuk mendukung karakteristik ini digunakan pengidentifikasi biometrik yang melekat pada setiap orang sebagai identitas yang unik.

Sebagai jaminan keamanan pada protokol CryptO-0N2, analisis telah dilakukan terhadap protokol ini. Analisis yang dilakukan adalah dengan menggunakan pendekatan verifikasi formal yaitu BAN Logic Approach (Prakasa, 2012). Analisis dilakukan untuk membuktikan bahwa pihak - pihak yang berkomunikasi saling percaya dengan apa yang dipertukarkan untuk menjamin keamanan dalam komunikasi tersebut. Analisis dengan menggunakan BAN Logic ini mempunyai kelemahan terkait dengan subyektivitas verifikator karena bergantung pada kemahiran verifikator untuk memodelkan logika, Pada tahun 2006, Cas Cremers melakukan publikasi terhadap penelitiannya terkait dengan suatu metodologi untuk analisis dan verifikasi formal terhadap suatu security protocol dalam suatu bentuk tool analisis yang dikenal dengan nama Scyther Tool (Cremers, 2006). Tool analisis ini dapat menganalisis jaminan secrecy dan authentication pada suatu protokol.

Verifikasi formal terhadap suatu protokol dapat dijamin obyektivitasnya dengan munculnya Scyther Tool. Pada makalah ini akan disajikan analisis terhadap protokol CryptO-0N2 dengan Scyther Tool serta analisis terhadap hasil verifikasinya terkait dengan jaminan secrecy dan authentication pada protokol tersebut.

\section{LANDASAN TEORI}

\subsection{Protokol CryptO-0N2}

Protokol CryptO-0N2 merupakan suatu protokol secure ubiquitus e-voting, yaitu protokol yang didesain untuk penggunaan biometric identifier sehingga dapat mendukung sistem yang bersifat ubiquitus serta fitur-fitur kriptografi untuk menjamin keamanan informasi selama $e$-voting berlangsung. (Prakasa, 2012). Ubiquitus merupakan suatu sistem yang memungkinkan manusia berinteraksi dengan komputer secara kontinyu, dimana saja, kapan saja dan bagaimana saja.

Protokol "CryptO-0N2" terdiri dari 2 (dua) proses, yaitu proses otentikasi dan voting. Proses otentikasi merupakan proses verifikasi untuk memeriksa apakah pemilih merupakan pemilih yang sah, sedangkan proses voting adalah proses merekapitulasi suara pilihan pemilih. Skema protokol ini adalah client - server sebagaimana yang terlihat pada Gambar 1 dibawah ini.

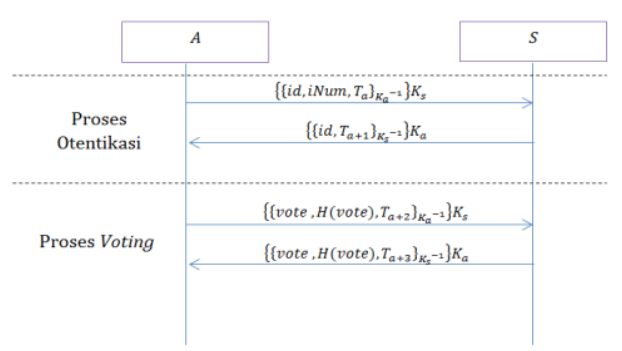

Gambar 1. Skema Protokol CryptO-0N2

Berikut adalah tabel yang menjelaskan properti yang digunakan dalam protokol CryptO-0N2. berikut:

Deskripsi protokol CryptO-0N2 adalah sebagai

a. Client dalam hal ini TPS akan mengirimkan pesan ke server berupa gabungan identitas pemilih, identification number, dan timestamp. Ketiga properti ini ditandatangani dengan menggunakan kunci privat TPS dan dienkripsi menggunakan kunci publik server. 
Tabel 1. Properti Protokol CryptO-0N2

\begin{tabular}{cc}
\hline simbol properti & arti \\
\hline id & Identitas pemilih \\
$T_{a}, T_{a+1}, T_{a+2}, T_{a+3}$ & Identification number \\
$K_{a}$ & Timestamps \\
$K_{s}$ & Kunci publik Tempat \\
$K_{a}{ }^{-1}$ & Pemungutan Suara (TPS) \\
$K_{s}{ }^{-1}$ & Kunci Publik Server \\
vote & Otentikasi \\
$H($ vote $)$ & Kunci privat Tempat \\
& Kunci Privat Server \\
& Otentikasi \\
\end{tabular}

b. Setelah server menerima pesan pertama, server ini akan mendekripsi pesan tersebut dengan menggunakan kunci privatnya. Kemudian hasil dekripsi tersebut akan didekripsi lagi mengggunakan kunci publik TPS. Dalam proses ini akan diverifikasi apakah pesan pertama ini benar-benar datang dari TPS. Selanjutnya ketiga properti didapatkan. Verifikasi juga dilakukan oleh server dengan cara memeriksa apakah identitas pemilih terdapat dalam data base pemilih, jika iya maka akan dilakukan pembangkitan identification number dengan inputan identitas pemilih tersebut. Nilai yang dibangkitkan akan dibandingkan dengan nilai identification number yang dikirimkan oleh TPS. Jika kedua nilai tersebut sama maka menyatakan pemilih merupakan pemilih yang sah. Jika demikian maka server otentikasi akan mengirimkan pesan ke TPS yang mengandung identitas pemilih dan timestamp plus 1 . Kedua properti ini akan ditandatangani dengan menggunakan kunci privat server otentikasi dan dienkripsi dengan menggunakan kunci publik TPS.

c. Setelah TPS menerima pesan kedua, maka TPS akan mendekripsi pesan tersebut dengan menggunakan kunci privatnya, selanjutnya hasil dekripsi tersebut akan didekripsi lagi dengan menggunakan kunci publik server. Selanjutnya didapatkan identitas pemilih dan timestamp plus 1. Kedua properti ini sebagai tanda bahwa pemilih dapat melakukan proses pemilihan. Selanjutnya pemilih akan melakukan proses pilihan. Kemudian, TPS akan mengirimkan pesan ketiga ke server yang berisi pilihan pemilih, nilai hash dari pilihan pemilih dan timestamp plus 2. Ketiga properti ini akan ditandatangani dengan menggunakan kunci privat TPS dan kemudian dienkripsi dengan menggunakan kunci publik server.

d. Setelah server menerima pesan ketiga, maka server akan mendekripsi pesan tersebut dengan menggunakan kunci privatnya, selanjutnya hasil dekripsi tersebut akan didekripsi lagi dengan menggunakan kunci publik TPS. Selanjutnya ketiga properti ini didapatkan. Server akan melakukan verifikasi terhadap nilai hash dari pilihan yang dikirimkan. Server akan melakukan penghitungan nilai hash dari pilihan yang dikirimkan oleh TPS. Jika nilai tersebut sama maka dapat diyakini bahwa tidak ada perubahan pilihan selama komunikasi berlangsung. Kemudian server memasukkan piilihan tersebut dalam database tabulasi suara. Sebagai notifikasi bahwa hasil pemilihan telah masuk ke dalam data base tabulasi suara maka server akan mengirimkan pesan kepada TPS yang berisi pilihan, nilai hash dari pilihan dan timestamp plus 3. Pesan ini kemudian ditandatangani dengan menggunakan kunci privat server dan kemudian dienkripsi menggunakan kunci publik TPS.

e. Setelah TPS menerima pesan keempat maka TPS akan melakukan dekripsi dengan menggunakan kunci privatnya. Kemudian hasil dekripsi tersebut akan didekripsi lagi menggunakan kunci publik TPS. Selanjutnya ketiga properti didapatkan, sebagai notifikasi dari server bahwa pilihan pemilih sudah masuk dalam database tabulasi suara.

\subsection{Scyther Tool Analyzer}

Scyther merupakan tool untuk melakukan analisis terhadap security protocol dengan perfect cryptography assumption, yaitu mengasumsikan bahwa keseluruhan fungsi kriptografi adalah perfect dalam artian pihak yang tidak berwenang tidak dapat mempelajari apapun dari sebuah ciphertext pesan kecuali pihak tersebut mengetahui kunci untuk mendekripsi pesan tersebut (Cremers, 2006). Tool ini dapat digunakan untuk menemukan permasalahan yang mungkin muncul dalam rangka mendesain suatu protokol kriptografi, salah satunya dengan mengetahui berbagai serangan yang mungkin muncul. Tool ini juga dilengkapi dengan Graphical User Interface (GUI). Input dari Scyther Tool adalah deskripsi dari suatu security protocol yang meliputi propertinya sehingga dapat diperoleh klaim dari penggunaan properti tersebut dan mengevaluasinya. Evaluasi dilakukan terhadap klaim secrecy dan authentication. Klaim secrecy untuk memastikan kerahasiaan dari suatu pesan, sedangkan klaim authentication memastikan keberadaan dari mitra komunikasi (aliveness), mitra komunikasi tersebut aktif dan mengeksekusi setiap langkah protokol serta pihak pengirim (synchronisation) dan penerima menyelesaikan seluruh langkah protokol juga pihak penerima dan pengirim setuju dengan pesan yang dipertukarkan (agreement).

\section{METODE PENELITIAN}

Penelitian ini dilakukan dengan langkah langkah sebagai berikut: 
a. Mengkodekan deskripsi protokol CryptO-0N2 sesuai dengan format yang ditentukan oleh Scyther Tool. Tahap ini bertujuan untuk menkonversi deskripsi protocol sesuai dengan Bahasa yang dimengerti oleh Scyther Tool.

b. Melakukan verifikasi terhadap kode pada poin a dengan menggunakan Scyther Tool. Tujuan dari langkah ini adalah untuk menjalankan verifikasi terhadap kode yang telah dibuat sesuai dengan deskripsi protocol.

c. Melakukan observasi hasil verifikasi protokol CryptO-0N2 terhadap klaim sukses dan gagal.

Tujuan dari langkah ini adalah untuk memeriksa hasil verifikasi dari protokol. Suatu properti pada protokol di klaim sukses jika tidak ada serangan yang muncul terhadap klaim tertentu. Hal tersebut ditandai dengan status OK pada hasil Scyther tool.

d. Melakukan analisa terhadap dengan klaim yang gagal sesuai dengan grafik hasil verifikasi Scyther Tool. Tool ini akan menampilkan grafik serangan yang mugkin terjadi jika satu atau banyak klaim dinyatakan gagal.

\section{PEMBAHASAN DAN ANALISIS}

Analisis terhadap protokol CryptO-0N2 adalah dengan melakukan evaluasi terhadap klaim secret dan authentication pada protokol. Input dari Scyther Tool adalah deskripsi protokol CrptO-0N2disesuikan dengan aturan pengkodean protokol pada tool ini. Berikut adalah tabel yang mendeskripsikan protokol CryptO-0N2 yang telah disesuaikan dengan aturan pengkodean Scyther Tool.

Tabel 2. Deskripsi Protokol CryptO-0N2 yang Telah

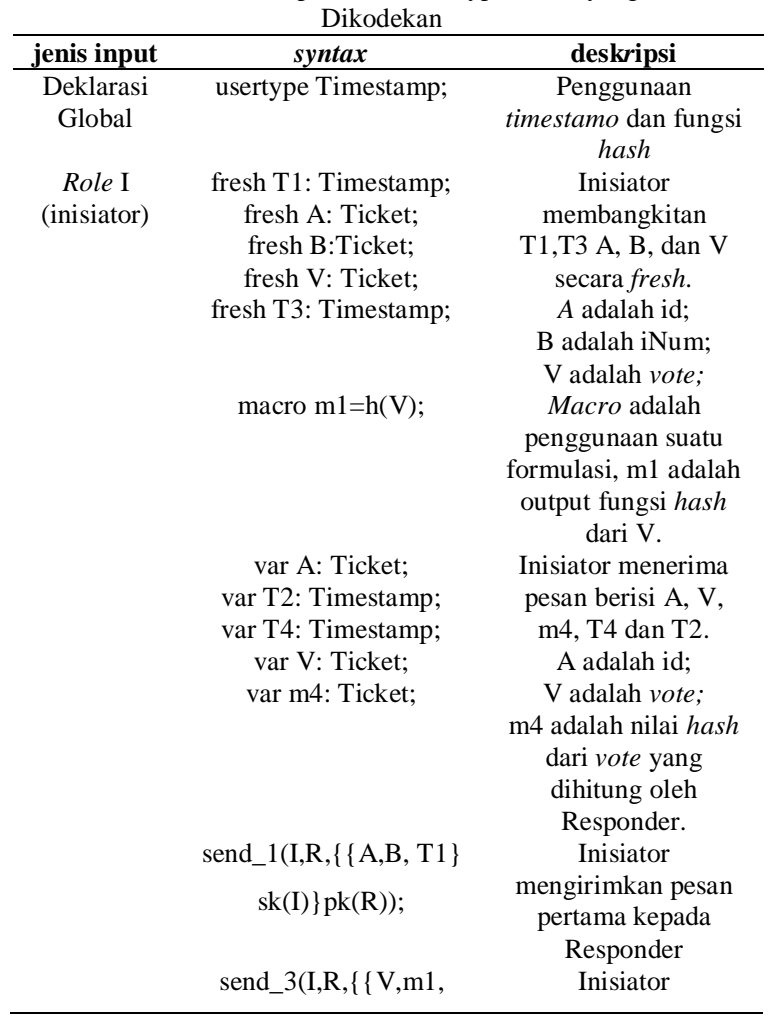

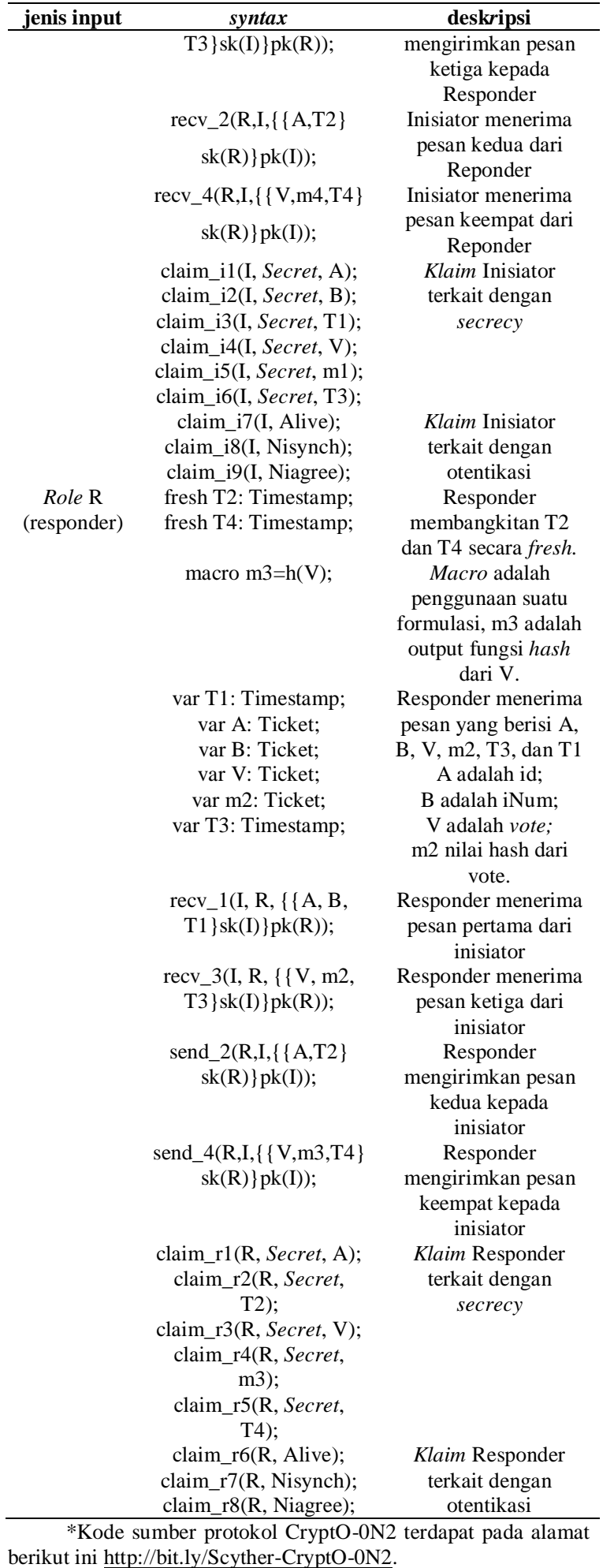

Dari tabel 2 diatas dapat dilihat terdapat 17 klaim terkait dengan secrecy dan authentication untuk Role I maupun R. Langkah selanjutnya setelah mengkodekan protokol adalah melakukan verifikasi terhadap deskripsi protokol tersebut. Gambar 2 menunjukkan hasil verifikasi protokol CryptO-0N2. Dari 17 klaim, terdapat 10 klaim yang dinyatakan benar atau OK dan 7 klaim dinyatakan gagal atau FAIL. 


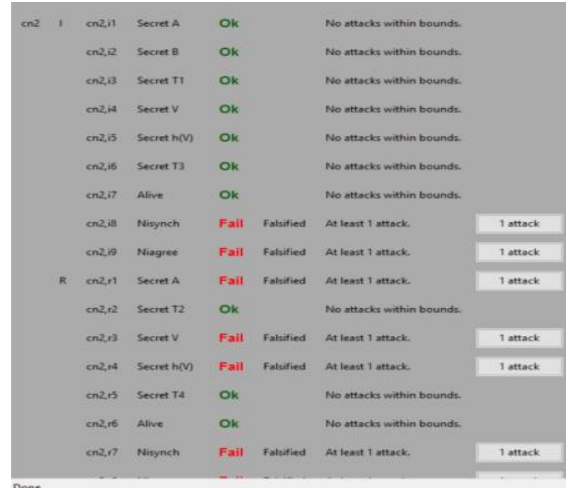

Gambar 2. Hasil Verifikasi Protokol CryptO-0N

Berikut adalah penjelasannya:

a. Seluruh klaim secret dari Role I (Inisiator) adalah benar. Hal ini dapat diartikan bahwa parameter yang dikirimkan oleh Inisiator dijamin kerahasiaannya;

b. Tidak seluruh klaim secret dari Role $\mathrm{R}$ (Responder) adalah benar. Hal ini dapat diartikan bahwa tidak semua parameter yang dikirimkan oleh Responder dijamin kerahasiaannya. Parameter yang dinyatakan secret adalah T2 dan T4, sedangkan parameter yang gagal dinyatakan secret adalah $\mathrm{A}, \mathrm{V}$, dan $\mathrm{h}(\mathrm{V})$;

c. Seluruh klaim authentication tipe Aliveness adalah benar. Hal ini diartikan bahwa baik Inisiator juga Responder telah mengeksekusi semua events;

d. Seluruh klaim authentication tipe Synchronisation adalah tidak benar. Hal ini dapat diartikan bahwa terdapat setidaknya satu attack sehingga klaim tersebut tidak benar;

e. Seluruh klaim authentication tipe Agreement adalah tidak benar. Hal ini dapat diartikan bahwa terdapat setidaknya satu attack sehingga kaim tersebut tidak benar.

Setiap klaim yang dinyatakan FAIL dapat ditemukan informasi berupa skema serangan yang menyebabkan klaim tersebut gagal. Seluruh skema (gambar 3 sampai gambar 9) dari klaim - klaim tersebut terdapat pada http://bit.ly/attackonCryptO0N2.

Berikut adalah penjelasan dari setiap klaim yang dinyatakan gagal:

a. Pada jenis klaim authentication tipe synchronisation oleh Role I (Inisiator)

Klaim authentication dengan tipe synchronisation pada protokol Crypt0-ON2 tidak terpenuhi atau ditemukan kondisi yang tidak memenuhi untuk klaim tersebut. Klaim authentication tipe synchronisation merupakan klaim authentication yang paling kompleks dari pemodelan authentication dari verifikasi Scyther. Klaim ini mensyaratkan setiap run dari protokol yang diinisiasi oleh agen I harus terkorenspondensi satu-satu dengan pihak $\mathrm{R}$. Pada Gambar 3 dapat dilihat bahwa terdapat run yang tidak unik yaitu recv_1 yang dapat dilakukan melalui run\#2 dan run \#3, sehingga terdapat dua run atas satu sesi protokol. Hal ini menyebabkan kondisi klaim authentication tipe synchronisation tidak terpenuhi.

b. Pada jenis claim authentication tipe agreement oleh Role I (Inisiator)

Klaim authentication dengan tipe agreement pada protokol Crypt0-ON2 tidak terpenuhi atau ditemukan kondisi yang tidak memenuhi untuk klaim tersebut. Klaim authentication tipe synchronisation merupakan klaim authentication yang juga relatif kompleks dari pemodelan authentication dari verifikasi Scyther. Klaim ini mensyaratkan setiap run dari protokol yang diinisiasi oleh agen I harus sepakat dengan data yang dipertukarkan dengan pihak R. Pada Gambar 4 dapat dilihat bahwa terdapat run yang tidak unik yaitu send_1 yang dapat dilakukan melalui run\#2 dan run \#3, sehingga terdapat dua run atas satu sesi protokol. Hal ini menyebabkan kondisi klaim authentication tipe agreement tidak terpenuhi.

c. Pada jenis klaim secret dengan parameter A oleh Role R (responder)

Klaim secret pada parameter A dapat digagalkan dengan skenario yaitu Eve melakukan impersonasi Bob, sehingga pesan send_1 yang harusnya dienkripsi dengan kunci publik Bob, tetapi dienkripsi dengan kunci publik Eve, sehingga Eve mampu melakukan dekripsi atas pesan yang terkandung di dalam send_1. Dengan demikian klaim secret pada parameter A menjadi gagal. Alur skenario serangan tersebut dapat dilihat pada Gambar 5.

d. Pada jenis klaim secret dengan parameter $\mathrm{V}$ oleh Role R (responder)

Klaim secret pada parameter $\mathrm{V}$ dapat digagalkan dengan skenario yaitu Eve melakukan impersonasi Bob, sehingga pesan send_1 yang harusnya dienkripsi dengan kunci publik Bob, tetapi dienkripsi dengan kunci publik Eve, sehingga Eve mampu melakukan dekripsi atas pesan yang terkandung di dalam send_1. Dengan demikian klaim secret pada parameter $\mathrm{V}$ menjadi gagal. Alur skenario serangan tersebut dapat dilihat pada Gambar 6.

e. Pada jenis klaim secret dengan parameter $\mathrm{h}(\mathrm{V})$ oleh Role R (responder)

Klaim secret dengan parameter $\mathrm{h}(\mathrm{V})$ dapat digagalkan dengan skenario Eve membangkitkan seluruh parameter pada pesan, sehingga Bob menerima pesan seolah-seolah dari Alice. Eve mempelajari format pesan untuk dikirimkan ke Alice sampai Bon mengirimkan pesan pada send_4 ke Eve, dengan demikian Eve mempeRoleh pesan yang ditandatangani oleh Bob, pesan ini kemudian oleh Eve di kirim ke Alice dengan dienkripsi menggunakan kunci publik Alice. Alur skenario serangan tersebut dapat dilihat pada Gambar 7. 
f. Pada jenis klaim authentication tipe synchronisation oleh Role $\mathrm{R}$ (responder)

Klaim authentication dengan tipe synchronisation pada protokol Crypt0-ON2 tidak terpenuhi atau ditemukan kondisi yang tidak memenuhi untuk klaim tersebut. Klaim authentication tipe synchronisation merupakan klaim authentication yang relatif kompleks dari pemodelan authentication dari verifikasi Scyther. Klaim ini mensyaratkan setiap run dari protokol yang diinisiasi oleh agen I harus berkorespondensi satu - satu. Pada Gambar 8 dapat dilihat bahwa terdapat run yang tidak unik yaitu send_1 yang dapat diterima pada recv_1 juga recv_3, sehingga terdapat dua penerimaan atas satu sesi protokol. Hal ini menyebabkan kondisi klaim authentication tipe synchronisation tidak terpenuhi

g. Pada jenis klaim authentication tipe agreement oleh Role R (responder)

Klaim authentication dengan tipe agreement pada protokol CryptO-ON2 tidak terpenuhi atau ditemukan kondisi yang tidak memenuhi untuk klaim tersebut. Klaim authentication tipe synchronisation merupakan klaim authentication yang juga relatif kompleks dari pemodelan authentication dari verifikasi Scyther. Klaim ini mensyaratkan setiap run dari protokol yang diinisiasi oleh agen I harus sepakat dengan data yang dipertukarkan dengan pihak R. Pada Gambar 9 dapat dilihat bahwa terdapat run yang tidak unik yaitu send_1 yang dapat diterima pada recv_1 dan recv_3, sehingga terdapat dua penerimaan atas satu pengiriman. Hal ini menyebabkan kondisi klaim authentication tipe agreement tidak terpenuhi.

\section{KESIMPULAN DAN SARAN}

Telah dilakukan analisis terhadap protokol CryptO-0N2 dengan menggunakan Scyther Tool. Dari 17 klaim terkait secrecy dan authentication terdapat 10 klaim yang sukses dan 7 klaim yang gagal dengan rincian sebagai berikut:

a. Klaim Sukses (OK)

1) Klaim secret $\mathrm{A}, \mathrm{B}, \mathrm{T} 1, \mathrm{~V}, \mathrm{~h}(\mathrm{~V}), \mathrm{T} 3, \mathrm{~T} 2, \mathrm{~T} 4$ oleh Role I;

2) Klaim authentication berjenis alive oleh Role I

3) Klaim authentication berjenis alive oleh Role $\mathrm{R}$

b. Klaim Gagal (FAIL)

1) Klaim authentication berjenis Nisynch dan Niagree oleh Role I;

2) Klaim secret A, V, h(V) oleh Role R;

3) Klaim Klaim authentication berjenis Nisynch dan Niagree oleh Role R;

Setidaknya terdapat satu attack terhadap protokol jika klaim secrecy dan authentication dinyatakan gagal. Skema serangan dapat dipelajari untuk proses perbaikan protokol CryptO-0N2 agar diperoleh hasil sukses untuk seluruh klaim.

\section{DAFTAR PUSTAKA}

ANTARANEWS. Pilkades Sistem e-voting Diterapkan di Musirawas [online] Tersedia di:

https://www.antaranews.com/berita/405457 /pilkades-sistem-e-voting-diterapkan-dimusirawas $>$ [Diakses 15 Oktober 2018]

CREMES, CAS, 2006. Scyther - Semantics and Verification of Security Protocols. Eindhoven: Technische Universtait Eindhoven.

CREMES, CAS, 2006. The Scyther Tool, [online] Tersedia di: https://www.cs.ox.ac.uk/people/cas.cremers /scyther/> [Diakses 26 Mei 2017]

JATENGPOS. Tak Hanya Pilkades, Pemilihan Ketua RW di Boyolali pun pakai e-voting [online] Tersedia di: < http://www.jatengpos.com/2017/01/takhanya-pilkades-pemilihan-ketua-rw-diboyolali-pun-pakai-e-voting-782695> [Diakses 15 Oktober 2018]

KOMPAS. Rekam Jejak Pemilu dari Masa ke Masa, [online] Tersedia di: < https://nasional.kompas.com/read/2018/08/ 06/15380041/rekam-jejak-pemilu-darimasa-ke-masa> [Diakses 9 Oktober 2018]

LIPUTAN6. Kecurangan Pemilu, [online] Tersedia di: http://www.liputan6.com/tag/kecuranganpe -milu> [Diakses 24 Mei 2017]

MENEZES, A, dkk., 1997. Handbook of Applied Cryptography. Florida: CRC Press Inc.

PRAKASA, P.Y., 2012. Rancang Bangun Aplikasi Secure E - Voting dengan Implementasi Protokol CryptO-0N2 untuk Pemilihan Umum Elektronis. Jakarta: Universitas Gunadharma

SCHENEIER, BRUCE, 1996. Applied Cryptography, Second Edition: Protocols, Algorithms, and Source Code in C. New Jersey: John Willey and Son Inc.

TRIBUNNEWS. Pemilihan Kepala Desa di Banyuasin Ini Menggunakan e-voting [online] Tersedia di: < http://www.tribunnews.com/regional/2015/ 11/11/pemilihan-kepala-desa-di-banyuasinini-menggunakan-e-voting> [Diakses 15 Oktober 2018]

WOLF, PETER, 2011. Introducing Electronic Voting. Swedia: International IDEA Publication Office Bulls Graphic. 